\title{
NEUROPEPTIDES
}

\section{Gastrin Releasing Peptide (GRP) Binding Sites in Human Bronchi}

\author{
J. N. BARANIUK*, J. D. LUNDGREN*, J. H. SHELHAMER, $\dagger$ and M. A. KALINER* \\ *Allergenic Diseases Section, Laboratory of Clinical Investigation, Building 10, Room 11-C-205, National \\ Institute of Allergy and Infectious Disease, Bethesda, MD 20892, USA; tCritical Care Department, \\ Clinical Center, NIH, Bethesda, MD, USA (Reprint requests to MAK)
}

Abstract-The autoradiographic binding site of gastrin releasing peptide (GRP), the 27 amino acid mammalian form of bombesin, were examined in human bronchial mucosa. ${ }^{125}$-GRP bound specifically to submucosal glands and the epithelium. There was limited binding to vessels and bronchial smooth muscle. These observations suggest that GRP or GRP immunoreactive peptides which are present in nerve fibres and pulmonary neuroendocrine cells, may act upon glandular GRP receptors to induce mucus secretion, but that GRP would probably have little effect on vascular permeability or tracheobronchial smooth muscle tone.

\section{Introduction}

Gastrin releasing peptide (GRP) is a 27 amino acid $(2859 \mathrm{~g} / \mathrm{mol})$ mammalian peptide (1). The Cterminal decapeptide, which is essential for receptor recognition and biological activity, shares sequence homology with bombesin, a 14 amino acid amphibian peptide (2). Other GRP immunoreactive peptides (GRP-irp) include GRP[1827] and unidentified peptides in human bronchoalveolar lavage fluid (3). GRP-irp are located in nerve fibres $(1,4)$ and pulmonary neuroendocrine cells (1), and may act as neurotransmitters (5) and neuroregulatory hormones $(1,6)$. GRP and bombesin are growth factors in fetal (7), normal (8), and neoplastic (9) respiratory tissues (1). GRP-irp are produced by small cell lung carcinoma cell lines

Date received 27 September 1991

Date accepted 3 October 1991
(10). Bombesin stimulate glandular secretion from both human and guinea pig nasal mucosa in vivo $(11,12)$. In vitro, GRP stimulates mucus secretion from cat trachea (13) and human nasal mucosa (14). Both lactoferrin, a product of submucosal gland serous cells (15), and ${ }^{3} \mathrm{H}$-glucosaminelabelled respiratory glycoconjugates were released from human nasal mucosa (14). GRP is also a stimulant of pancreatic exocrine secretion (16) and a participant in the central and vagal control of gastric mucosal homeostasis (17).

In order to examine the potential roles of GRP in the lower respiratory tract, ${ }^{125}$ I-GRP binding sites were localized in human bronchial mucosa using autoradiography.

\section{Methods}

Human lung specimens were obtained from patients undergoing thoracotomy for carcinoma. 


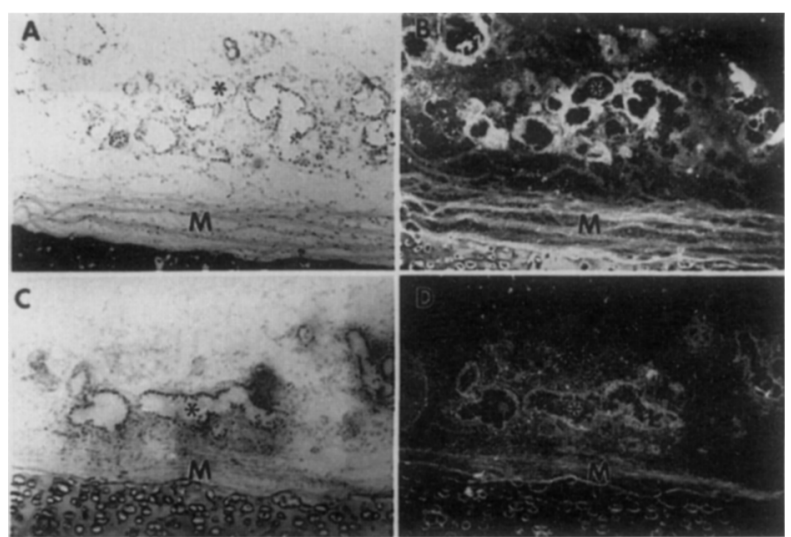

Fig. $1{ }^{12 s}$ I-GRP binding sites in human bronchial mucosa. (A) Brightfield image of submucosal glands ( $\left.{ }^{*}\right)$, tracheobronchial smooth muscle (M) and cartilage counterstained with toluidine blue. The bar represents $100 \mu \mathrm{m}$. (B) Darkfield image of (A) showing ${ }^{125}$ I-GRP binding to submucosal glands $\left({ }^{*}\right)$. The silver grains are very dense over the glands. Limited numbers of grains are seen over the bronchial smooth muscle (M). (C) Brightfield image of an adjacent section treated with excess GRP. (D) Darkfield image of (C) demonstrating that the addition of excess GRP ablated the binding of ${ }^{125}$ I-GRP to the glands $\left({ }^{*}\right)$ and smooth muscle $(\mathrm{M})$.

Blocks of perihilar tissue were frozen in 2-methylbutane for $30 \mathrm{~s}$ and stored at $-70^{\circ} \mathrm{C}$ until required. Cryostat sections $(10 \mu \mathrm{m}$ thick) were thaw mounted onto gelatinized slides, and warmed to room temperature. The slides were washed in CMRL media with aprotinin (400 kallikrein inhibitory units per ml, Sigma Chemical Co., St. Louis, MO, USA) and $0.5 \%$ bovine serum albumin for $30 \mathrm{~min}$ at $25^{\circ} \mathrm{C}(13,14)$. Slides were incubated for $75 \mathrm{~min}$

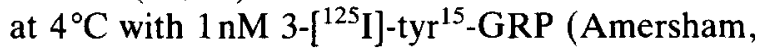
Arlington Heights, IL, USA) in CMRL/aprotinin/ BSA. Specific binding was determined by adding $1 \mathrm{nM}{ }^{125}$ I-GRP with and without $2 \mu \mathrm{M}$ unlabelled GRP. After incubation, slides were washed 4 times each for $30 \mathrm{~s}$ with CMRL/aprotinin/BSA at $4^{\circ} \mathrm{C}$ and dried with cold, dry air. Slides were dipped in melted nuclear track emulsion (NTB-2, Eastman Kodak, Rochester, NY, USA) diluted 1:1 with water and stored at $4{ }^{\circ} \mathrm{C}$ in light tight boxes. At intervals emulsion coated slides were removed and developed in Kodak reagents. Slides were counterstained with toluidine blue prior to darkfield microscopy.

\section{Results}

${ }^{125}$ I-GRP bound specifically to the epithelium and submucosal glands (Figs 1, 2, and 3). Submucosal glands expressed ${ }^{125}$ I-GRP binding sites most prominently (Figs 1 and 2). Both mucous and serous cells of submucosal glands bound ${ }^{125}$ I-GRP. Secretory ducts also expressed ${ }^{125}$ I-GRP binding sites. Epithelial cells diffusely bound ${ }^{125}$ I-GRP, and there was no apparent preference for goblet cells or other cell populations (Fig. 3). The silver grain density was higher over glands than over epithelium, and longer time exposures were required to see grain development over the epithelium suggesting that the ${ }^{125}$ I-GRP binding site density was higher in the glands. Vessel walls exhibited very limited ${ }^{125}$ I-GRP binding (Fig. 3). The types of vessels and cells containing the GRP binding sites could not be determined. Bronchial smooth muscle also displayed limited ${ }^{125}$ I-GRP binding (Fig. 1). The addition of excess GRP ablated the binding ${ }^{125}$ I-GRP to submucosal glands, epithelium, vessels, and smooth muscle indicating the specificity of the binding sites.

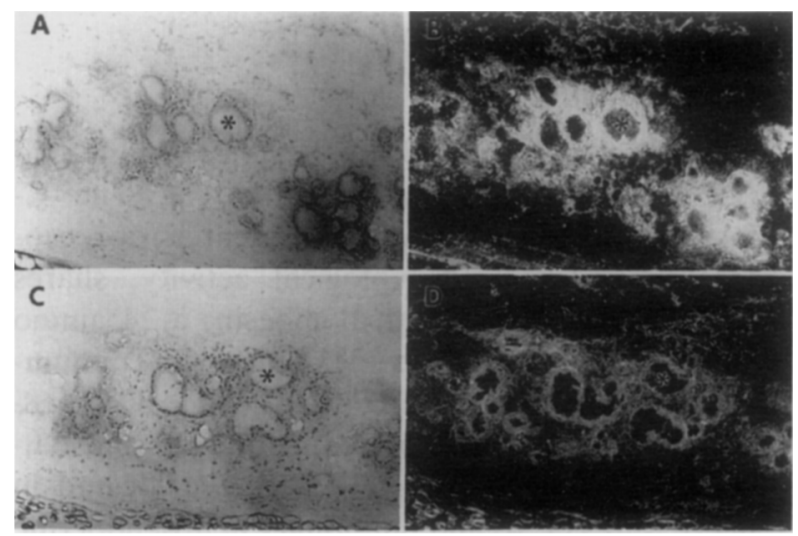

Fig. 2 125I-GRP binding sites in human bronchial mucosa. (A) Brightfield image of submucosal glands $\left({ }^{*}\right)$ counterstained with toluidine blue. The bar represents $100 \mu \mathrm{m}$. (B) Darkfield image of (A) showing a very high density of silver grains indicating ${ }^{125}$ I-GRP binding to both the mucous and serous cells of the submucosal glands $\left({ }^{*}\right)$. The silver grains are very dense over the glands. (C) Brightfield image of an adjacent section treated with excess GRP. (D) Darkfield image of (C) demonstrating that the addition of excess GRP ablated the binding of ${ }^{125}$ I-GRP to the glands $\left(^{*}\right)$. 


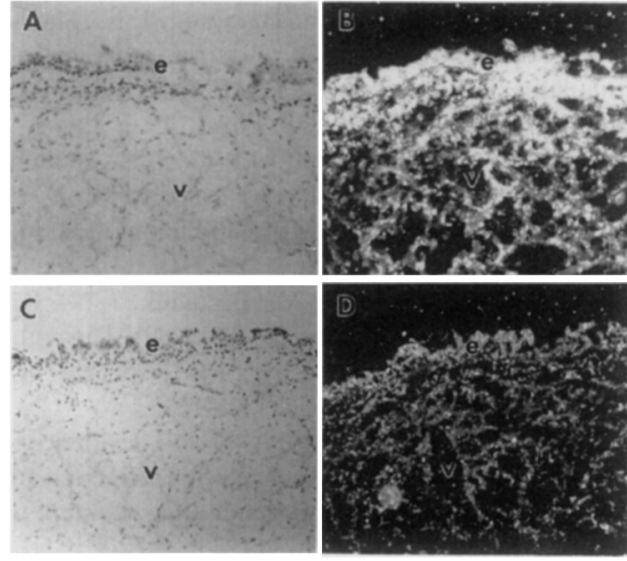

Fig. 3 125I-GRP binding sites in human tracheobronchial mucosa. (A) Brightfield image of the epithelium (e) and submucosal plexus of vessels $(v)$. The bar represents $100 \mu \mathrm{m}$. (B) Darkfield autoradiographic image (A) showing silver grains which represent ${ }^{125}$ I-GRP binding sites. Silver grains are seen over the epithelium (e) and vessels walls (v). (C) Brightfield image of an adjacent section treated with excess GRP. (D) Darkfield autoradiographic image of (C). The addition of $1 \mu \mathrm{M}$ GRP ablated the specific binding of ${ }^{125}$ I-GRP to the epithelium (e) and vessels (v).

\section{Discussion}

${ }^{125}$ I-GRP binding sites abounded on submucosal glands and the epithelium. This finding is consistent with the known functions of GRP. GRP and bombesin are potent stimuli of serous cell, mucous cell and possibly goblet cell secretion from human, cat and guinea pig upper and lower respiratory mucosa in vitro and in vivo (11-14). Bombesin nasal provocation in humans induces both serous and mucous cell secretion without increasing vascular permeability (11). Bombesin is a vasoconstrictor in canine tracheal vessels (18), and can stimulate bronchoconstriction in the guinea pig (19).

Because of the limited supply of human tissue, it was not possible to examine the capacity of GRP to stimulate glandular secretion, vascular permeability or muscle contraction in human tracheobronchial tissue or to quantify receptor numbers. However, the distribution of ${ }^{125}$ I-GRP binding sites suggests that GRP would preferentially affect glandular and epithelial cell functions.

The potential sources of GRP-irp in human pulmonary tissue are diverse. Neuroendocrine cells may be the primary source in humans $(3,20$, 21). GRP-irp may be present in nociceptive sensory neurons of either afferent vagal or dorsal root ganglion origin $(5,22)$. GRP-immunoreactive material has been identified in feline peritracheal ganglion cells (13) which may belong to the intrinsic nervous system of the tracheobronchial tree, or be parasympathetic post-ganglionic cell bodies.

The possible mechanisms that govern the release of GRP-irp into the pulmonary milieux are also diverse. Neuroendocrine cells may respond to chronic cigarette smoke by increasing GRP-irp content $(3,21)$. If GRP-irp are present in nociceptive sensory neurons $(5,14,22)$, they may be released with other colocalized neuropeptides by axon response mechanisms. Axon reflexes have been shown to release substance $P$, neurokinin $A$ and calcitonin gene related peptide from sensory neurons in rat nasal mucosa and rat tracheobronchial mucosa $(23,24)$. Axon reflexes may contribute to the pathogenesis of asthma (25). GRP-irp release by axon reflex mechanisms, or after capsaicin treatment, has not yet been examined. If present in ganglionic cells, then parasympathetic stimuli may induce the release of GRP-irp.

Based upon the autoradiographic data presented here, GRP or GRP-irp may be specific regulators of glandular secretion in human pulmonary mucosa. This finding may be of pathological importance in settings where increased amounts of GRP or GRP-irp are generated. Could the GRPirp found in bronchoalveolar lavage fluid of cigarette smokers (3) play a role in mucus hypersection and chronic bronchitis? Given the limited density of binding sites on human vascular and bronchial smooth muscle, GRP likely has negligible direct effects on tracheobronchial smooth muscle tone and vascular tone or permeability.

\section{Acknowledgements}

JDL supported in part by the Danish Medical Research Council. JNB supported by grants from the Proctor and Gamble Co. Inc. and Schering Research. 


\section{References}

1. Sunday, M. E., Kaplan, L. M., Motoyama, E., Chin, W. W. and Spindel, E. R. (1988). Gastrin releasing peptide (mammalian bombesin) gene expression in health and disease. Lab. Invest. 59: 5-24.

2. Anastasi, A. V., Erspamer, A. and Bucci, M. (1971). Isolation and structure of bombesin and alytesin, two analogous active peptides from the skin of the European amphibians Bombina and Alytes. Experientia 27: 166-167.

3. Aguayo, S. M., Kane, M. A., Talmadge, E. K., Jr., Schwartz, M. I., Grauer, L. and Miller, Y. E. (1989). Increased levels of bombesin-like peptides in the lower respiratory tract of asymptotic cigarette smokers. J. Clin. Invest. 84: 1105-1113.

4. Tsutsumi, Y. (1988). Immunohistochemical localization of gastrin releasing peptide in normal and diseased human lung. Ann. N. Y. Acad. Sci. 547: 336-350.

5. Holtzer, P. (1988). Local effector functions of capsaicinsensitive sensory nerve endings: involvement of tachykinins, calcitonin-gene related peptide and other neuropeptides. Neurosci. 24: 739-768.

6. Kentrote, S., Dees, W. L. and McCann, S. M. (1988). Evidence for a physiological role of hypothalamic gastrinreleasing peptide to suppress growth hormone and prolactin release in the rat. Proc. Natl. Acad. Sci. USA 85: 953-957.

7. Spindel, E. R., Sunday, M. E., Hofler, H., Wolfe, H. J., Habener, J. F. and Chin, W. W. (1987). Transient elevation of mRNAs encoding gastrin releasing peptide (GRP), a putative pulmonary growth factor, in human fetal lung. J. Clin. Invest. 80; 1172-1179.

8. Willey, J. C., Lechner, J. F. and Harris, C. C. (1984), Bombesin and the C-terminal tetradecapeptide of gastrin releasing peptide are growth factors for normal human bronchial epithelial cells. Exp. Cell. Res. 153: 245-248.

9. Cuittitta, F., Carney, D. N., Mulshine, J., Moody, T. W., Fedorko, J., Fiscler, A. and Minna, J. D. (1985). Bombesin-like peptides can function as autocrine growth factors in human small cell lung cancer. Nature 316: 823-826.

10. Moody, T. W., Lebovic, G. S., Carney, D. N. and Korman, L. Y. (1988). Bombesin/gastrin releasing peptide-like peptides and receptors in small cell lung cancer. Int. J. Neurosci. 40: 141-148.

11. Baraniuk, J. N., Silver, P. B., Lundgren, J. D., Cole, P., Kaliner, M. A. and Barnes, P. J. (1991). Bombesin stimulates mucous cell and serous cell secretion in human nasal provocation tests. Am. J. Physiol. in press.

12. Gawin, A., Baraniuk, J. N. and Kaliner, M. (1990). The effects of gastrin releasing peptide (GRP) and analogues on guinea pig nasal mucosa. Am. Rev. Respir. Dis. 141: A173.
13. Lundgren, J., Ostrowski, N., Baraniuk, J. N., Shelhamer, J. and Kaliner, M. (1990). Gastrin releasing peptide stimulates glycoconjugate release from feline tracheal explants. Am. J. Physiol. 258: L68-L74.

14. Baraniuk, J. N., Lundgren, J., Goff, J, , Peden, D., Merida, M., Shelhamer, J. and Kaliner, M. A. (1990). Gastrin releasing peptide (GRP) in human nasal mucosa. J. Clin. Invest. 85: 998-1005.

15. Raphael, G. D., Jeney, E. V., Baraniuk, J. N., Kim, I., Meredith, S. D. and Kaliner, M. A. (1989). The pathophysiology of rhinitis: Lactoferrin and lysozyme in nasal secretions. J. Clin. Invest. 84: 1528-1535.

16. Shinozaki, H. and Funokoshi, A. (1988). Evidence for the direct action of gastrin releasing peptide (GRP) on amylase secretion from rat pancreatic acini: an assessment using a perfusion system. Jap. J. Physiol. 38: 299-307.

17. Skak-Nielsen, T., Holst, J. J. and Nielsen, O. V. (1988). Role of gastrin releasing peptide in the neural control of pepsinogen secretion from the pig stomach. Gastroenterology 95: 1216-1220.

18. Salonen, R. O., Webber, S. E. and Widdicombe, J. G. (1988). Effects of neuropeptides and capsaicin on the canine tracheal vasculature in vivo. $\mathrm{Br}$. J. Pharmacol. 95: $1262-1270$.

19. Impicciatore, M. and Bertaccini, G. (1973). The bronchoconstrictor action of the tetradecapeptide bombesin in the guinea pig. J. Pharm. Pharmacol. 25: 872-875.

20. Polak, J. M. and Bloom, S. R. (1985). Occurrence and distribution of regulatory peptides in the respiratory tract. Recent Results Cancer Research 99: 1-16.

21. Tabassian, A. R., Nylen, E. S., Linnoila, I., Snider, R. H., Cassidy, M. M. and Becker, K. L. (1989). Stimulation of hamster pulmonary neuroendocrine cells and associated peptides by repeated exposure to cigarette smoke. Am. Rev. Respir. Dis. 140: 436-440.

22. Panula, P., Hadji, H. A., Constantinou, C. and Yang, T. (1983). Immunohistochemical localization of bombesin/ gastrin releasing peptide and substance $P$ in primary sensory neurons. J. Neurosci. 3: 2021-2029.

23. Hua, X. Y. (1986). Tachykinins and calcitonin gene related peptide in relation to peripheral functions at capsaicinsensitive neurons. Acta Physiol. Scand. 127: 1-45.

24. Saria, A., Martling, C. R., Yan, Z., TheodorssonNorheim, E., Gamse, R. and Lundberg, J. M. (1988). Release of multiple tachykinins from capsaicin-sensitive sensory nerves in the lung by bradykinin, histamine, dimethyl peperazinium, and vagal nerve stimulation. Am. Rev. Respir. Dis. 137: 1330-1335.

25. Barnes, P. J. (1986). Asthma as an axon reflex. Lancet 1: 242-245. 